\title{
DESENVOLVIMENTO E AVALIAÇÃO DE UM DOCUMENTÁRIO PARA SOCIALIZAÇÃO DA LEI N. 10.639/2003
}

\author{
Leandra Aparecida Mendes dos Santos Rodrigues \\ Mayara Lustosa de Oliveira Barbosa
}

Resumo

O objetivo deste artigo foi descrever o processo de elaboração, produção, aplicação e avaliação de um documentário na busca da socialização da Lei n. 10.639/2003. Desenvolveu-se uma pesquisa de campo, descritiva e exploratória com uma abordagem qualiquantitativa na análise dos dados. Aplicou-se questionário pré-teste a 29 estudantes do $8^{\circ}$ ano do ensino fundamental II da cidade de Pires do Rio, Goiás, antes da exibição do documentário e, posteriormente, um questionário pós-teste. Considerou-se que o documentário trouxe a socialização e conhecimento da Lei n. 10.639/2003 e, também, promoveu sensibilização quanto a necessidade de práticas para a discussão do racismo e preconceito a fim de se promover a verdadeira efetivação da respectiva Lei.

Palavras-chave: Lei n. 10.639/2003; documentário; relações étnico-raciais.

\section{DEVELOPMENT AND EVALUATION OF A DOCUMENTARY TO SOCIALIZE THE LAW 10.639/03}

\begin{abstract}
The objective of this article was to describe the process of elaboration, production, application and evaluation of a documentary in the search for the socialization of Law $10.639 / 2003$. We developed a field, descriptive and exploratory research with a quali-quantitative approach in data analysis. A pre-test questionnaire was applied to 29 8th grade students of the elementary school II in the city of Pires do Rio, Goiás, before the screening of the documentary, and then a post-test questionnaire. It was considered that the documentary brought the socialization and knowledge of Law n. 10.639/2003 and also promoted awareness of the need for practices to discuss racism and prejudice in order to promote the true effectiveness of this Law.
\end{abstract}

Keywords: Law n. 10.639/2003; documentary; ethnic-racial relations.

\section{DESARROLLO Y EVALUACIÓN DE UN DOCUMENTAL PARA SOCIALIZAR LA LEY N 10.639/03}

Resumen

El objetivo de este artículo fue describir el proceso de elaboración, producción, aplicación y evaluación de un documental en la búsqueda de la socialización de la Ley 10.639/03. Se desarrolló una investigación de campo, descriptiva y exploratoria con un enfoque cuali-cuantitativo en el análisis de los datos. Se aplicó un cuestionario pre-test a 29 alumnos del $8^{\circ}$ año de educación básica II de la ciudad de Pires do Rio, Goiás, antes de la proyección del documental y luego un cuestionario post-test. Se consideró que el documental aportó la socialización y el conocimiento de la Ley n. 10.639/2003 y también promovió la concienciación sobre la necesidad de que las prácticas discutan el racismo y los prejuicios para promover la verdadera eficacia de su Ley.

Palabras clave: Ley n. 10.639/2003; documental; relaciones étnico-raciales. 


\section{INTRODUÇÃO}

Mesmo diante da realidade de uma nação multicultural (CANEN, 2007), ainda nos deparamos com situações de preconceito e racismo que interferem negativamente na vida social e escolar dos estudantes. Porquanto, o racismo é um fenômeno estrutural e histórico que tende a inferiorizar os negros da população brasileira, contribuindo para um contexto marcado pela discriminação (CAMARGO et al., 2019).

Esse contexto de discriminação é intensificado pela visão eurocêntrica de formação da nossa sociedade que supervaloriza a história e cultura europeia (NASCIMENTO, 1998; CEDRAZ, 2020). Desse modo, essa situação encontra campo propício no contexto escolar e nos currículos, sendo necessário buscar formas de intervir positivamente nesse processo (GOMES, 2012).

Pesquisas revelam que elementos segregadores como raça e pobreza afetam severamente o desempenho escolar dos estudantes negros e pioram o racismo na escola (LOGAN, MINCA, ADAR, 2012; MCGEE, MARTIN, 2011). Ademais, situações de preconceito e racismo nos ambientes escolares, ainda são ignoradas, naturalizadas e fortalecidas pela ideia de uma democracia racial (CARVALHO, FRANÇA, 2019). Isto interfere não só no acesso, mas também, na permanência com êxito dos estudantes que pertencem a essa parcela da população.

Com o objetivo de reparar essa situação que se tornou obrigatório o ensino de História e Cultura Afro-Brasileira em todo o currículo escolar, por meio da promulgação, em 9 de janeiro de 2003, da Lei n. 10.639/03, que altera a Lei de Diretrizes e Bases de 1996 para reforçar a valorização e o respeito as diferentes culturas que formam a nossa identidade cultural. Porém, na realidade escolar ainda acontece a inoperância desta Lei, e uma das especificidades se resume a apresentações em datas comemorativas, normalmente, nas semanas dos dias 13 de maio e 20 de novembro (RODRIGUES, 2011; RODRIGUES, 2020).

Dado o exposto, é de fundamental importância pensar em propostas práticas que permitam a efetiva implementação do que está previsto na Lei n. 10.639/03. Dentre essas propostas, pode ser destacada a necessidade do desenvolvimento de produtos educacionais voltados para as questões étnico-raciais e que favoreçam o processo de implementação da Lei n. 10.639/03 (OLIVEIRA, SILVA, 2015). Pois, grande parte das pesquisas apontam que a falta de material didático adequado é um dos limitantes para a sua implementação (SOUZA, PEREIRA, 2013; SANTANA, OLIVEIRA, MACHADO E SILVA, 2018).

Assim, este artigo descreve o processo de planejamento, produção, aplicação e avaliação de um documentário na busca da socialização da Lei n. 10.639/03. Intencionou-se mostrar a importância de se trabalhar a História e a cultura afro-brasileira em uma turma de $8^{\circ}$ ano, da segunda fase do ensino fundamental de Pires do Rio, Goiás (GO). Desse modo, objetivou-se não somente o reconhecimento de diferentes culturas, mas a melhoria da afirmação da identidade negra dos estudantes afrodescendentes.

Sendo assim, buscou-se: 1) investigar como estão sendo consideradas as diferenças étnicoraciais no ambiente escolar; 2) buscar a socialização da Lei n. 10.639 por meio da estruturação de um roteiro fundamentado nas premissas nela presentes; 3) elaborar um documentário com participação de estudantes e docente de uma instituição educacional, visando a socialização da Lei n. 10.639/03; 4) promover uma reflexão crítica sobre o preconceito e racismo na escola; 5) analisar e validar, por meio de questionários de opinião, a aplicabilidade do produto educacional elaborado. 


\section{PROCEDIMENTOS METODOLÓGICOS}

\section{Caracterização da pesquisa}

Este estudo consiste em uma pesquisa de campo, ou seja, é "[...] utilizada com o objetivo de conseguir informações e/ou conhecimentos a cerca de um problema para o qual se procura uma resposta” (MARCONI, LAKATOS, 2018, p. 69). Segundo Gil (2008, p. 133) “[...] muitos estudos de campo possibilitam a análise estatística de dados, sobretudo quando se valem de questionários ou formulários para coleta de dados". Desse modo, os questionários elaborados para esse estudo objetivaram analisar os pontos alcançados e as possíveis alterações que deverão ser feitas para aprimoramento do produto educacional.

Trata-se de uma pesquisa de natureza aplicada e descritiva-exploratória, pois aborda a descrição, registro, análise e interpretação de fenômenos atuais e visa aplicação de um produto educacional (MARCONI, LAKATOS, 2018). Por fim, com relação à abordagem, é uma pesquisa qualiquantitativa, pois combina a análise quantitativa e qualitativa dos dados com o propósito de aprofundar o entendimento dos resultados (MARCONI, LAKATOS, 2018).

\section{Público-alvo}

O documentário teve como alvo estudantes do ensino fundamental II. Para elaboração, contou-se com a participação de uma professora e cinco estudantes da segunda fase do ensino fundamental de uma escola da rede pública estadual de Pires do Rio/GO.

A aplicação e avaliação do produto foi feita com 29 estudantes do $8^{\circ}$ ano do ensino fundamental II em uma escola da rede particular de ensino de Pires do Rio. A não aplicação do documentário na escola em que foi produzido foi devido à solicitação dos participantes.

\section{Planejamento E DESENVOLVIMENTO DO PRODUTO EDUCACIONAL}

Os objetivos do documentário centraram-se em apresentar a Lei n. 10.639 e promover uma reflexão sobre o preconceito e o racismo na escola. Para alcançá-los foram utilizados alguns passos para construção do vídeo, seguindo as especificações das etapas descritas por Kindem e Musburger (1997), que de forma geral dividem o processo de produção em três etapas: pré-produção, produção e pós-produção.

A pré-produção consiste na preparação do projeto do documentário a ser produzido. Nesta etapa, foi criado o site www.cultura-afro-brasileira96.webnode.com, por meio do qual o documentário estaria disponível. Com relação ao conteúdo do documentário, a pré-produção considera todas as atividades que serão realizadas, desde o início da ideia e inclui a construção da sinopse, do argumento e do storyboard.

A sinopse é um resumo geral do que será exibido no vídeo. Ao construí-la as pesquisadoras sintetizaram nos seguintes tópicos: 1) inicialmente a Lei será apresentada por meio de uma narração acompanhada de legenda em fundo escuro, 2) posteriormente a cidade alvo e a escola serão mostradas, de modo que se compreenda o contexto da localidade; 3) o objetivo da Lei foi esclarecido e reforçado, antes do início das falas; e por fim 4) trechos dos depoimentos são apresentados e uma fala encerra o produto.

Após a estruturação da sinopse, foi construído o argumento, ou seja, o intermediário entre a sinopse e o roteiro, o qual descreveu brevemente como se desenvolveria a ação. A partir de então, o roteiro foi finalizado e refinado, com a descrição detalhada de todas as ações, a fim de orientar a 
produção. Por fim, foi feito um storyboard, ou seja, a representação das cenas do roteiro em forma de desenhos sequenciais, semelhante a uma história em quadrinhos, de modo a facilitar a visualização das cenas.

Após o preparo inicial, seguiram-se as etapas de produção, momento em que foram feitas as filmagens das cenas que formam o documentário, incluindo não somente os vídeos, mas também as imagens e áudios para a organização da mensagem a ser transmitida. A entrevista com estudantes e com a professora participante durou em média 50 minutos e as filmagens na escola aconteceram em dois momentos, contando com a presença da pesquisadora e um técnico de filmagem.

Por fim, foram conduzidas as etapas de edição e finalização do vídeo, as quais compõem a pós-produção. Esta fase consistiu, também, na gravação de áudios de narração e edição de legendas para tornar o vídeo mais acessível. Para a edição, foi utilizado o programa Wondershare Filmora Profissional versão oito e teve a duração de 18 dias. Toda esta etapa de edição foi acompanhada pela pesquisadora para que se conseguisse chegar ao resultado ao qual o documentário foi criado.

\section{Levantamento de dados: entrevistas e questionários}

Antes de receber os depoimentos, primeiramente, foi esclarecido aos estudantes as intenções da pesquisa e entregue o termo de consentimento livre esclarecido (TCLE) ${ }^{1}$ para ser assinado pelos pais e o termo de assentimento livre esclarecido (TALE) ${ }^{2}$ a ser assinado pelos estudantes. A professora participante também recebeu esclarecimentos sobre o objetivo do documentário e o TCLE.

Para receber os depoimentos dos estudantes foi feito um roteiro de entrevista. Sendo assim, ao realizarmos as entrevistas, teve-se em mente atuar como mediadores para o sujeito apreender sua própria situação de outro ângulo, conduzindo-os a procurar relações nas situações e a organizálas, tal como aponta Britto-Júnior e Feres-Júnior (2011). Avaliando seu meio social, os entrevistados podem ao mesmo tempo se autoavaliar e avaliar os contextos perante sua comunidade e perante a sociedade, legitimando-se como interlocutor e refletindo sobre questões em torno das quais talvez não se detivesse em outras circunstâncias (DUARTE, 2004).

Assim, a fim de estruturar uma entrevista coerente com nosso público-alvo, levando em consideração o exposto anteriormente, a proposta foi estruturada tendo em vista os passos descritos por Britto-Júnior e Feres-Júnior (2011) e a revisão bibliográfica sobre a construção do roteiro de entrevista a partir do levantamento dos elementos essenciais à sua elaboração, de Silva e Ferreira (2012).

A entrevista com os estudantes trouxe as questões: 1) Já recebeu algum apelido na escola? Alguma ofensa que o tenha deixado triste? 2) Como são as figuras de representação humana em seu livro didático? Você se sente representado? 3) Já vivenciou ou presenciou alguma situação marcante de preconceito e racismo que você possa contar? 4) Já participou de alguma atividade pedagógica em sua escola que promovesse a História e Cultura Afro-brasileira? 5) Caso a resposta à pergunta anterior tenha sido sim, conte como aconteceu essa atividade.

Para coletar os depoimentos da professora, também foi feito um roteiro de entrevista com as seguintes questões: 1) Você conhece a Lei n. 10.639/2003? 2) Se conhece do que trata esta Lei? 3) Já vivenciou ou presenciou alguma situação marcante, como aluno ou como professor, de preconceito e racismo que você possa contar? 4) Como você percebe as figuras de representação humana nos livros didáticos? Você percebe a representação das pessoas negras? 5) Já participou ou

\footnotetext{
${ }^{1}$ https://drive.google.com/file/d/1C-w83LQMCEBJTJrYVKjt udN3b27vQPS/view?usp=sharing

${ }^{2}$ https://drive.google.com/file/d/15kLXnCqwfTLyOkIeu8MgdtstQaSEBKfP/view?usp=sharing
} 
planejou alguma atividade pedagógica em sua escola que promovesse a História e Cultura Afrobrasileira?

Durante os depoimentos, foram gravados os vídeos dos estudantes e da professora pela própria pesquisadora e um técnico de filmagem. Para a análise das entrevistas com os estudantes foi feita análise de conteúdo seguindo os passos propostos por Bardin (2011). Na pré-análise, aconteceu a organização das entrevistas com o objetivo de constituir o corpus da pesquisa. Nesse momento, depois de ouvidos, os registros orais das entrevistas, que totalizaram 35 minutos, foram transcritos utilizando a Reshape $e^{3}$. Como o nível de acurácia ficou em 83,2\%, fez-se uma leitura flutuante da transcrição, em que se observou a necessidade de nova escuta e conferência de fidedignidade para elevar a precisão dos depoimentos.

$\mathrm{Na}$ exploração do material, o corpus foi analisado profundamente, com o objetivo de estabelecer as unidades de registro e unidades de contexto. Olhou-se para cada uma das entrevistas de maneira isolada, buscando as unidades de significação a partir de temas. Leu-se novamente cada uma das mensagens, buscando congruências e diferenças entre elas para o agrupamento em categorias de análise seguindo os princípios do método. As categorias foram definidas a posteriori tendo como direcionamento averiguar evidências de fortalecimento do racismo no contexto escolar para confirmar a necessidade do objetivo deste estudo que é mostrar a importância de se trabalhar a História e a cultura Afro-brasileira na educação básica.

Dentre as respostas dos estudantes (E) pôde-se definir quatro categorias: 1) existência de estereótipos; 2) falta de representatividade; 3) existência de racismo na escola; 4) inexistência de práticas de implementação da Lei n. 10.639/03. Por fim, concluindo as etapas, analisou-se os resultados encontrados na categorização e fez-se as inferências estabelecendo um paralelo com o depoimento da professora que também seguiu o mesmo parâmetro de transcrição.

Para a avaliação do produto educacional, no primeiro momento, foram investigados os conhecimentos prévios relacionados à Lei n. 10.639/03 e como estavam sendo consideradas e trabalhadas na escola as diferenças étnico-raciais. Tal análise diagnóstica deu-se por meio da aplicação de um questionário pré-teste elaborado via formulário do Google e disponibilizado no site desenvolvido.

O questionário pré-teste continha 2 questões abertas e 2 fechadas: 1) Você conhece a Lei n. 10.639? 2) Caso conheça, do que se trata esta Lei? 3) Você já viveu ou presenciou alguma situação de preconceito e racismo quanto às diferenças étnico-raciais na escola? e 4) Se sim, descreva a situação ocorrida brevemente.

Para a exibição do documentário, os estudantes dispunham de tabletes individuais e o processo aconteceu na sala de aula, durante duas aulas de $50 \mathrm{~min}$. A aplicação do documentário foi feita pelo professor regente da turma e, posteriormente, fez-se uma entrevista para averiguar a receptividade dos estudantes e a percepção do professor aplicador sobre a significância da exibição do documentário. A entrevista contou com as perguntas: 1) Qual a reação dos estudantes durante a aplicação do documentário? 2) Você gostou de aplicar o documentário? e 3) Você acha importante aplicar propostas nesse formato?

Após a aplicação do questionário pré-teste, aconteceu a exibição do produto educacional. Posteriormente, aplicou-se o questionário pós-teste, para avaliar a assimilação do conteúdo e medir o nível de satisfação com o documentário.

\footnotetext{
${ }^{3}$ A Reshape é uma plataforma online para transcrição de áudio ou vídeo e geração de legendas. O software converte áudio e vídeo em texto.

${ }^{4}$ https://tinyurl.com/yn2tzkyy
} 
O questionário pós-teste continha 2 perguntas abertas, 2 fechadas e 2 em escala Likert, utilizando uma escala de 5 pontos de concordância (DALMORO; VIEIRA, 2013). A saber: 1) Após assistir ao documentário, você responderia que conhece, ao menos parcialmente, o conteúdo da Lei n. 10.639/2003? 2) O que você entendeu sobre o que esta Lei propõe? 3) A Lei n. 10.639 já foi apresentada em algum momento em sua escola? 4) Se sim, em qual disciplina? 5) O que você achou do documentário? 6) Este documentário foi útil para você conhecer a Lei n. 10.639/2003?

\section{RESULTADOS E DISCUSSÃO}

\section{Resultado das entrevistas}

Para a análise de conteúdo das entrevistas foram estabelecidas categorias (BARDIN, 2011), as quais foram apresentadas na Tabela 1.

Tabela 1: Categorias que apontam possíveis evidências de fortalecimento do racismo no contexto escolar

\begin{tabular}{|c|c|c|}
\hline Categorias & Excerto das entrevistas & $\begin{array}{c}\text { Possíveis } \\
\text { evidências de } \\
\text { fortalecimento do } \\
\text { racismo no } \\
\text { contexto escolar }\end{array}$ \\
\hline $\begin{array}{l}\text { Categoria 1: } \\
\text { Existência de } \\
\text { estereótipos }\end{array}$ & $\begin{array}{l}\text { A1: “Que eu me recorde, aqui na escola, não. Mas em } \\
\text { outras escolas que eu estudei, já aconteceu. Na verdade, } \\
\text { já aconteceu deles fazerem comparações com objetos } \\
\text { pretos, por exemplo, como carvão, fita isolante e coisas } \\
\text { do tipo. Me chamavam de carvão, asfalto, fita isolante e } \\
\text { coisas do tipo". } \\
\text { A2: "A pessoa chamar de feia, essas coisas, mas eu não } \\
\text { ligo não. Fica rindo, sabe, da gente quando a gente } \\
\text { passa". } \\
\text { A3: "Tipo na outra escola teve um ano que eu sofri } \\
\text { bulling né. A menina veio falar do meu cabelo. Ela falava } \\
\text { que meu cabelo era Bombril, que não dava para } \\
\text { pentear". } \\
\text { A4: "Só umas piadinhas". } \\
\text { A5: "De preto macumbeiro, mas é brincadeira". }\end{array}$ & $\begin{array}{l}\text { Os excertos } \\
\text { confirmam a } \\
\text { existência de } \\
\text { apelidos que } \\
\text { estereotipam os } \\
\text { estudantes negros no } \\
\text { contexto escolar. }\end{array}$ \\
\hline $\begin{array}{l}\text { Categoria 2: Falta } \\
\text { de } \\
\text { representatividade }\end{array}$ & $\begin{array}{l}\text { A1: "Nos livros de história, por exemplo, tem as figuras } \\
\text { lá de negros que representam muito na época da } \\
\text { escravidão, no Brasil colônia e na colonização de outros } \\
\text { países. Representando os negros quando eles eram } \\
\text { açoitados, em situação precária e péssima qualidade de } \\
\text { vida que eles viviam". } \\
\text { A2: "Não. Só de escravo essas coisas". } \\
\text { A3: "Só quando é escravo né. Mas custa aparecer né. } \\
\text { Gente moreninha, negra assim né". } \\
\text { A4: "Já vi sim, em histórias em quadrinhos. No livro de } \\
\text { história sim". } \\
\text { A5: "Não. Só de escravo". }\end{array}$ & $\begin{array}{l}\text { Os excertos } \\
\text { apontam para a falta } \\
\text { de representatividade } \\
\text { da população negra } \\
\text { nos materiais } \\
\text { didáticos. }\end{array}$ \\
\hline
\end{tabular}




\begin{tabular}{|c|c|c|}
\hline $\begin{array}{c}\text { Categoria 3: } \\
\text { Existência de } \\
\text { racismo na escola }\end{array}$ & $\begin{array}{l}\text { A1: "E já aconteceu de eu apanhar várias vezes, dias } \\
\text { seguidos, por conta da minha pele e por conta do meu } \\
\text { desempenho na escola". } \\
\text { A2: "Só na escola quando eu estudava aí as meninas não } \\
\text { gostavam de mim e ficavam todo dia me enchendo, mas } \\
\text { não era muita coisa não". } \\
\text { A3: "Ela falava que meu cabelo era Bombril, que não } \\
\text { dava para pentear. Isso foi no banheiro, aí eu saí } \\
\text { chorando e logo minha mãe me buscou lá e aí resolveu, } \\
\text { mas foi só aquela vez". } \\
\text { A4: "Eu não tinha amiga ainda, e me chamava de carvão } \\
\text { e quando eu chegava chamava. Ao invés de meu nome. } \\
\text { Aí os meninos, nesse dia me apelidaram de carvão me } \\
\text { chamou de macaca". } \\
\text { A5: "Começaram a me chamar de preto macumbeiro. Aí } \\
\text { eu comecei a ficar nervoso e fui pra cima bater". }\end{array}$ & $\begin{array}{l}\text { Os excertos } \\
\text { confirmam a } \\
\text { existência de } \\
\text { situações de racismo } \\
\text { em relação aos } \\
\text { traços fenotípicos da } \\
\text { população negra, } \\
\text { bem como aspectos } \\
\text { relacionados a } \\
\text { religiosidade. }\end{array}$ \\
\hline $\begin{array}{c}\text { Categoria 4: } \\
\text { Inexistência de } \\
\text { práticas de } \\
\text { Implementação da } \\
\text { Lei n. } 10.639 / 2003\end{array}$ & A1; A2; A3; A4; A5: “Não participei”. & $\begin{array}{l}\text { Os excertos } \\
\text { apontam a } \\
\text { inexistência de } \\
\text { práticas para a } \\
\text { implementação da } \\
\text { Lei n. } 10.639 / 2003 \\
\text { no contexto escolar } \\
\text { analisado. }\end{array}$ \\
\hline
\end{tabular}

Fonte: Elaborado pelas autoras.

Associando as respostas dos estudantes à resposta da professora pôde-se inferir que as respostas às perguntas: 1) Você conhece a Lei n. 10.639/2003? 2) Se conhece do que trata esta Lei? e 5) Já participou ou planejou alguma atividade pedagógica em sua escola que promovesse a História e Cultura Afro-brasileira? corroboram os resultados da categoria 4, já que a professora respondeu respectivamente "Se já, eu não sei se é essa. Não. Nada. Mas aqui na escola eu nunca vi e nunca presenciei”.

Sendo assim, reforçamos a concepção de que uma das maiores causas do fortalecimento do racismo no contexto escolar é a falta de formação dos professores para reconhecer as determinações da Lei n. 10.639/2003 e implementá-la em suas atividades pedagógicas (EUGÊNIO, SANTANA, 2018; ALVES, 2017).

Com relação à pergunta 3) Já vivenciou ou presenciou alguma situação marcante, como aluno ou como professor, de preconceito e racismo que você possa contar? atesta-se os resultados da categoria 3 e 1 , pois tem-se a confirmação de que o racismo perdura no contexto escolar. Uma vez que a professora relata:

Quando eu ainda estudava, eu já vivi algumas coisas assim e já vi também crianças que passaram por isso. Ela quando voltava da escola, e eu também, porque nós duas íamos e voltávamos da escola. Aí com um aluno, a gente estudava no Sagrado, com um aluno vinha atrás da gente falando assim: "Nega do sovaco fedorento, bate a bunda no cimento para ganhar 1.500", não sei se você lembra disso. Aí sabe, vinha atrás da gente.

Assim, confirma-se o racismo estrutural e sua longevidade histórica (CAMARGO, BENITE, 2019; ALMEIDA, 2019), pois tanto as respostas dos estudantes quanto da professora 
confirmam a existência de agressões em relação aos traços fenotípicos da população negra e continuam frequentes no contexto escolar (GOMES, MIRANDA, 2014; JESUS, 2018).

Quando questionada 4) Como você percebe as figuras de representação humana nos livros didáticos? Você percebe a representação das pessoas negras? Também se comprova a mesma percepção da categoria 2, reforçando a falta de representatividade da população negra nos materiais didáticos, pois a professora relatou "Lembro de ver da época da escravidão, a gente via era mais sobre isso, sobre a lei Áurea, que eu me lembro, vago de ter estudado, foi mais sobre isso, o que aconteceu na época dos escravizados".

O estudo de Barboza (2020) sobre a representação do negro e do índio nos livros didáticos brasileiros dos anos 1970 até o ano 2000 relata a pouca representatividade da população negra e afirma a necessidade de uma representação equilibrada das etnias que povoam o Brasil para que todos se sintam representados.

\section{Resultado do pré-teste}

Como exposto anteriormente, no primeiro momento, antes da exibição do documentário, foi aplicado o questionário pré-teste para a investigação do conhecimento sobre a Lei n. $10.639 / 2003$ e para averiguar se na escola eram trabalhadas atividades que envolvem a valorização da cultura afro-brasileira.

Quanto ao conhecimento da Lei n. 10.639/2003 a maioria (93\%) dos respondentes afirmam não conhecer. Apenas dois estudantes (E) conheciam a respectiva Lei, como pode ser observado no relato: E1: "Se trata da cultura afro-brasileira e que também devemos respeitá-la".

Quando os estudantes foram questionados se já haviam presenciado alguma situação de preconceito e racismo na escola quanto às diferenças étnico-raciais, os resultados são quase nivelados, sendo que 52\% já presenciaram e 48\% não. Dos 14 estudantes que mencionaram ter presenciado alguma situação de preconceito e racismo, os relatos a seguir sintetizam de modo explícito ataques comuns vivenciados por estudantes: E1: "Eu já estudei com um colega que todos chamavam ele de macaco"; E2: "Falaram que o cabelo da menina era Bombril só porque era crespo".

Uma análise sobre enunciações de estudantes do $8^{\circ}$ ano de ensino fundamental, relacionadas às questões étnico-raciais, também foi realizada por Nunes e Wanderer (2019). As autoras apontam a existência de práticas racistas, as quais foram descritas pelos estudantes, com respostas similares com as obtidas no questionário pré-teste dessa pesquisa. Ademais, destacam que os estudantes afirmaram ser alvos de "olhar torto", ou mesmo de comentários preconceituosos tecidos em relação a eles ou a amigos e familiares.

Pôde-se observar com a aplicação do pré-teste, bem como, com a entrevista à professora, durante a construção do documentário, o desconhecimento da Lei. Da mesma forma, pelo grande número de situações de racismo que muitos afirmam ter presenciado, supõe-se que as determinações da Lei não têm sido levadas ao contexto escolar, fortalecendo a extrema necessidade de ações como esta, de modo a alterar o atual contexto vivenciado nas escolas.

Como mencionado por Benite et al. (2018), a prática pedagógica precisa fomentar o diálogo entre as diferenças, promovendo o questionamento de discursos que reforçam as discriminações e os estereótipos e sejam capazes de articular os conteúdos dos currículos e a diversidade histórica e cultural. 
Resultado da exibição do documentário

Em um segundo momento, o documentário foi apresentado a uma turma de $8^{\circ}$ ano do ensino fundamental II de um colégio da rede particular de ensino, mediante a autorização do gestor desta instituição.

Quanto à pergunta sobre a reação dos estudantes durante a aplicação do documentário, o professor aplicador relatou que alguns estudantes se pronunciaram durante a apresentação demonstrando indignação e sentimentos de repúdio ao racismo diante do que assistiram. Após a exibição do documentário, o professor aplicador relatou que os estudantes se sentiram sensibilizados, alguns se emocionaram com os depoimentos e outros relataram vivências de preconceito e racismo como nos depoimentos a seguir: E1: "Os apelidos, às vezes me incomodam"; E2: "Me chamam assim".

Diante desse contexto, é notável que o racismo precisa ser discutido na sala de aula, a qual é um espaço de formação intelectual e social. Para tanto, é necessário descolonizar os currículos, a fim de se contemplar a realidade social e promover uma reflexão sobre as culturas silenciadas (GOMES, 2012).

Sobre ter gostado de aplicar o documentário e a importância de propostas nesse formato, o professor regente mostrou-se tocado da importância de trabalhar propostas pedagógicas que contemplem a História e valorização da cultura afro-brasileira. Quanto a significância da exibição do documentário, o professor mencionou que: "Foi muito importante a discussão levantada com o documentário, gostaríamos de apresentá-lo nas outras turmas da escola". Sendo assim, destacase a importância da sensibilização dos professores e, também, a necessidade de estarem preparados para desenvolverem a Educação das Relações Étnico-Raciais (HENRIQUES, CAVALLEIRO, 2005).

Um ponto crucial para a implementação da Lei é a formação dos profissionais da educação. Como esta legislação é considerada como uma oportunidade de reparação da retaliação causada em mais de três séculos de uma cultura racista desenvolvida no Brasil (CONCEIÇÃO, 2019), precisa ser levada à escola por meio destes profissionais. Neste sentido, Santos (2005) aponta para a extrema necessidade de qualificação de profissionais da educação para desenvolverem uma educação que contemple a diversidade.

Muitos estudos, também, apontam que a maioria dos professores não conhecem a Lei, e ser preciso uma maior atenção à formação de professores para que saibam desenvolver a Educação das Relações Étnico-Raciais (PEREIRA et al., 2018; GILLAM, 2016; GUIMARÃES, 2015; SULEIMAN, 2014; CASTRILLON, AZEVEDO, 2018; SOUZA, CRUSOÉ, MOREIRA, 2016).

\section{Resultado do pós-teste}

Enfim, para analisar se o produto educacional trouxe algum impacto na socialização da Lei n. 10.639/2003, se proporcionou reforço e reflexão sobre a valorização das culturas na escola, aplicou-se o questionário pós-teste. Desse modo, após a exibição do documentário os estudantes foram questionados se reconheciam a Lei n. 10.639/2003. Teve-se um resultado significativo, pois, nesse momento, $100 \%$ dos estudantes reconheceram a Lei.

Quanto ao questionamento sobre do que a Lei propõe, todos os estudantes relataram que compreenderam, associando-a com as práticas de racismo e preconceito na escola. Como pode-se observar no relato: E5: "Propõe a busca em relação aos nossos direitos, lutar para que possamos viver em um mundo onde as pessoas possam nos aceitar do jeito que somos ou agimos, nos respeitando". 
Ao serem questionados quanto a apresentação da Lei n. 10.639/2003 em alguma disciplina, apenas seis estudantes afirmaram ter ouvido nas disciplinas de Português, Redação, Geografia e História. Contudo, a própria Lei n. 10.639/2003 determina o ensino de História e Cultura AfroBrasileira em todo o currículo escolar, em especial nas áreas de Educação Artística e de Literatura e História Brasileiras. Porém, seria mais eficaz trabalhar as prescrições da Lei de maneira interdisciplinar, estabelecendo um diálogo entre todas as áreas do conhecimento (LIMA, SOUSA, ARAÚJO, 2016).

Quanto ao nível de satisfação sobre o documentário, os estudantes foram questionados utilizando a escala Likert e os resultados confirmam que os 48,3\% gostaram e 51,7\% gostaram muito da exibição.

Vale ressaltar que os elementos visuais apresentados no documentário permitem a sensibilização para se refletir sobre as relações étnico-raciais. Pois, segundo Tuan (2012, p. 22) dentre "[...] os cinco sentidos tradicionais, o homem depende mais conscientemente da visão do que dos demais sentidos para progredir no mundo. Ele é predominantemente um animal visual".

Desse modo, as técnicas de vídeo podem ser praticadas dentro e fora da sala de aula (PERON, 2011, p. 444), sendo possível por meio da apresentação de elementos visuais representar a realidade escolar e provocar o repensar sobre as relações étnico-raciais.

Quanto à utilidade do documentário para promover o conhecimento da Lei n. 10.639/2003 os estudantes afirmam ter sido válido, pois 34,5\% declararam ter sido útil e 65,5\% muito útil. Então, o documentário pôde, além de sensibilizar, trazer informação, pois a técnica de vídeo é uma linguagem carregada de intencionalidade, com objetivos claros da problemática a ser atacada e dos encaminhamentos necessários para promover uma reflexão e um posicionamento diante do assunto tratado (MOURA, PASCHOAL, 2018).

Diante do resultado positivo da aplicação do vídeo, pôde-se perceber que a utilização de vídeos pode ajudar na discussão sobre o racismo e preconceito, mas também pode ser um recurso a ser utilizado para trabalhar a cultura e a história africana a afro-brasileira. Sendo assim, o vídeo cumpre a função de ser uma alternativa para a implementação da Lei n. 10.639/2003 (CAMARGO et al., 2019). O que é corroborado por Pereira (2011) que utilizou um documentário para a construção de novos conhecimentos sobre história e cultura afro-brasileira, no qual o autor menciona que a dinâmica do vídeo foi fundamental para construir conhecimentos sobre a cultura africana e afro-brasileira.

Propôs-se com este documentário buscar a socialização da Lei n. 10.639/2003, bem como promover uma reflexão crítica sobre as diferenças étnico-raciais, destacando a importância do contato com a pluralidade cultural e étnica que formam o ambiente escolar ao qual os estudantes estão inseridos. A intenção foi contribuir para a formação social dos estudantes, pois, sabe-se que a escola pode ser considerada um "[...] local onde as primeiras noções de ser negro, numa realidade de exclusão e invisibilidade, ganham sentido e interferem na trajetória futura" (GONÇALVES, 2018, p. 5).

\section{CONSIDERAÇÕES FINAIS}

Situações de preconceito e racismo que acontecem na escola, muitas vezes, são a causa de um fracasso escolar e evasão dos estudantes afrodescendentes Pior ainda, essas microagressões (GERSHENSON et al., 2016; HUBER, SOLORZANO, 2015) são ignoradas, naturalizadas, reforçando a invisibilidade do negro. 
Esse estudo confirma a necessidade de reflexão e discussão sobre o racismo e preconceito, bem como sobre o processo de implementação da Lei n. 10.639/2003. Durante as entrevistas para a elaboração do documentário, os depoimentos dos estudantes e de uma professora sobre as experiências vividas no contexto escolar reforçam a necessidade de se promover essa reflexão. Pois, como observado na transcrição das entrevistas e nas cenas do vídeo este problema está latente no interior do contexto escolar.

$\mathrm{Na}$ aplicação do pré-teste observou-se que a maioria dos estudantes não conhecem a Lei n. $10.639 / 2003$, porém $52 \%$ dos estudantes participantes da pesquisa já presenciaram situações de preconceito e racismo na escola quanto às diferenças étnico-raciais. O depoimento da professora, também, confirma o desconhecimento desta legislação. O que reforça a necessidade do desenvolvimento de atividades para o reconhecimento e valorização da cultura africana e afrobrasileira. Ainda, há que se destacar que a formação inicial e continuada de professores é uma questão fundamental no processo de implementação da Lei n. 10.639/2003 e o desenvolvimento da Educação das Relações Étnico-Raciais.

Outro fator a ser destacado é a importância da sensibilização dos professores para desenvolverem as determinações da Lei, no caso do documentário, mostrou-se ser instrumento favorável. Também, durante a exibição, conforme relatos do professor aplicador, alguns estudantes se pronunciaram durante a apresentação demonstrando indignação e sentimentos de repudia ao racismo diante do que assistiram. Sendo assim, evidenciando que o racismo precisa ser discutido na sala de aula, a qual é um espaço de formação intelectual e social.

Com a aplicação do questionário pós-teste, teve-se um resultado significativo, pois todos os estudantes que participaram da pesquisa reconheceram a Lei após assistirem ao documentário. Contudo, os resultados apontam a necessidade de práticas para a efetivação da Lei em todas as disciplinas. Visto, que a legislação em si não terá eficácia se não for levada à realidade da escola. Destaca- se, então, o papel fundamental do professor no desafio de implementação da respectiva Lei, pois práticas pedagógicas que trabalhem o respeito à diversidade e às diferenças é a proposta para a verdadeira efetivação da Lei n. 10.639/2003.

Os estudantes foram unânimes ao aprovar a exibição do documentário, o que enfatiza que os elementos visuais utilizados no vídeo contribuíram para o ideal de socialização e sensibilização, sendo, também, útil para o reconhecimento da Lei n. 10.639/2003, como mostraram os questionários. Como perspectiva futura pretende-se estender a aplicação do documentário a um maior número de estudantes da educação básica. Intenciona-se, também, aplicar em uma escola pública para se fazer um paralelo entre uma instituição pública e uma particular.

\section{REFERÊNCIAS}

ALMEIDA, Silvio. Racismo estrutural. Pólen Produção Editorial LTDA, 2019.

ALVES, Marta Mariano. Lei 10.639/03, formação docente e NEABs: a democratização do currículo como um desafio para a educação brasileira. Cadernos do Aplicaşão, v. 30, p. 33-47, 2017.

BARBOZA, Rainiel Lopes. As representações do negro e do índio nos livros didáticos brasileiros (1970-2000). Revista Eletrônica Discente do Curso de História-UFAM, v. 4, n. 1, p. 362-374, 2020.

BARDIN, Laurence. Análise de conteúdo. 4. ed. Lisboa: Edições 70, 2011.

BENITE, Anna Maria Canavarro; BASTOS, Morgana Abranches; VARGAS, Regina Nobre; FERNANDES, Fernanda Silva; FAUSTINO, Gustavo Augusto Assis. Cultura africana e afrobrasileira e o ensino de química: estudos sobre desigualdades de raça e gênero e a produção científica. Educação em Revista, Belo Horizonte, v. 34, p. 1-36, 2018.

BRASIL. Lei n. 10.639/2003, de 9 de janeiro de 2003. Brasília: MEC, 2003. 
BRITTO-JÚNIOR, Álvaro Francisco; FERES-JÚNIOR, Nazir. A utilização da técnica da entrevista em trabalhos científicos. Evidência, Araxá, v. 7, n. 7, p. 237-250, ago. 2011.

CAMARGO, Marysson Jonas Rodrigues; VARGAS, Regina Nobre; SILVA, Juvan Pereira da; BENITE, Cláudio Roberto Machado; BENITE, Anna Maria Canavarro. Do Ferreiro a Magnetita: o vídeo educativo como alternativa para a implementação da Lei 10.639/03. Química nova escola, São Paulo, v. 41, n. 3, p. 224-232, ago. 2019.

CAMARGO, Marysson Jonas Rodrigues; BENITE, Anna Maria Canavarro. Educação para as relações étnico-raciais na formação de professores de química: sobre a Lei 10.639/2003 no Ensino Superior. Quimica Nova, São Paulo, v. 42, n. 6, p. 691-701, 2019.

CANEN, Ana. O multiculturalismo e seus dilemas: implicações na educação. Comunicação e Política, v. 25, n. 2, p. 91-107, 2007.

CARVALHO, Daniela Melo da Silva; FRANÇA, Dalila Xavier de. Estratégias de enfrentamento do racismo na escola: uma revisão integrativa. Educaşão \& Formação, Aracaju, v. 4, n. 12, p. 148-168, 2019.

CASTRILLON, Maria de Lourdes Fanaia; AZEVEDO, Lucy Ferreira. Literatura africana infantojuvenil na escola básica. Crítica Educativa, Sorocaba, v. 4, n. 2, p. 190-202, jul./dez, 2018.

CEDRAZ, Ana Cláudia do Carmo. Educação escolar quilombola: um olhar sobre as práticas educativas da escola Maria Rita Marcelina da Silva, na comunidade quilombola do Maracujá, Conceição do Coité-Bahia. In: XIX Encontro de História da Anpub-Rio, Rio de Janeiro, p. 1-10, 2020. CONCEIÇÃO, Alexsandro Gomes da. O racismo no Brasil, o Movimento Negro e a Lei 10.639/03. Revista Africa e Africanidades, Rio de janeiro, ano XII, n. 31, p. 1-19, ago. 2019.

DALMORO, Marlon; VIEIRA, Kelmara Mendes. Dilemas na construção de escalas Tipo Likert: o número de itens e a disposição influenciam nos resultados? Revista Gestão Organizacional, Pernambuco, v. 6, n. 3, p. 161-174, 2013.

DUARTE, Rosália. Entrevistas em pesquisas qualitativas. Educar em Revista, n. 24, p. 213-225, 2004. EUGÊNIO, Benedito Gonçalves; SANTANA, Fabiana. Relações étnico-raciais e o trabalho com a Lei 10.639/03: análise de uma experiência com formação docente. Ensino \& Pesquisa, v. 16, n. 1, p. 58-73, 2018.

FILHO, João Bernardo da Silva. Os discursos verbais e iconográficos sobre Negros em Livros Didáticos de História. 143f., 2005. Dissertação de Mestrado em Educação, FAE/UFMG, Belo Horizonte, 2005. GERSHENSON, Seth; HOLT, Stephen B.; PAPAGEORGE, Nicholas W. Who believes in me? The effect of student-teacher demographic match on teacher expectations. Economics of education review, v. 52, p. 209-224, 2016.

GIL, Antônio Carlos. Como elaborar projetos de pesquisa. 4. ed. São Paulo: Atlas, 2008.

GILLAM, Reighan. Learning to Transgress: Law 10.639 and Teacher-Training Classrooms in São Paulo, Brazil. Transforming Anthropology, v. 24, n. 1, p. 70-79, 2016.

GOMES, Nilma Lino. As práticas pedagógicas com as relações étnico-raciais nas escolas públicas: desafios e perspectivas. In: GOMES, Nilma Lino (org.). Práticas pedagógicas de trabalho com relações étnico-raciais na escola na perspectiva da Lei no 10.639/03. 1. ed. Brasilia: MEC; Unesco, 2012.

GOMES, Nilma Lino; MIRANDA, Shirley Aparecida de. Gênero, raça e educação: indagações advindas de um olhar sobre uma academia de modelos. Poiésis, v. 8, n. 13, p. 91-111, 2014.

GONÇALVES, Rosângela Cristina. Quinze anos da Lei 10.639/03 - avanços e retrocessos. In: Rev. Iberoam. Patrim. Histórico-Educativo. Campinas, v. 4, n. 2, p. 434-439, jul./dez. 2018.

GUIMARÃES, Selva. The teaching of Afro-Brazilian and indigenous culture and history in Brazilian basic education in the $21^{\text {st }}$ century. Policy Futures in Education, v. 13, n. 8, p. 939-948, 2015. 
HENRIQUES, Ricardo; CAVALlEIRO, Eliane. Educação e Políticas Públicas Afirmativas: elementos da agenda do Ministério da Educação In: SANTOS, Sales Augusto dos (org.). Ações afirmativas e combate ao racismo nas Américas. Brasília: Ministério da Educação: UNESCO, 2005.

HUBER, Lindsay Pérez; SOLORZANO, Daniel G. Racial microaggressions as a tool for critical race research. Race Ethnicity and Education, v. 18, n. 3, p. 297-320, 2015.

JESUS, Rodrigo Ednilson de. Mecanismos eficientes na produção do fracasso escolar de jovens negros: estereótipos, silenciamento e invisibilização. Educaşão em Revista, Belo Horizonte, n. 34, p. 1-19, 2018.

KINDEM, Gorham; MUSBURGE, Robert B. Introduction to media production: from analog to digital. Focal Press, Boston, 1997.

LIMA, Lucineide Amorim; SOUSA, Rayron Lennon Costa; ARAÚJO, Geovana Oliveira de. A literatura africana e afro-brasileira: o viés literário e suas possibilidades para um trabalho com a diversidade. Ensino \& Multidisciplinaridade, São Luís, v. 2, n. 1, p. 74-83, jan./jun., 2016.

LOGAN, John R.; MINCA, Elisabeta; ADAR, Sinem. The Geography of Inequality: Why Separate Means Unequal in American Public Schools. Sociol Educ. v. 85, n. 10, p. 1-21, 2012.

MARCONI, Marina de Andrade; LAKATOS, Eva Maria. Técnicas de pesquisa: planejamento e execução de pesquisas, amostragens e técnicas de pesquisas, elaboração, análise e interpretação de dados. 7. São Paulo: Atlas, 2018.

MCGEE, Ebony O.; MARTIN, Danny B. You would not believe what I have to go through to prove my intellectual value! stereotype management among academically successful black mathematics and engineering students. American Educational Research Journal, v. 48, n. 6, p. 13471389, 2011.

MOURA, Jeani Delgado Paschoal; PASCOAL, Wilson Aparecido. Percepção e sensibilização do ambiente escolar por meio de fotografias e produção de documentário. Geosaberes, Fortaleza, v. 9, n. 17, p. 1-10, jan./abr. 2018.

NASCIMENTO, Abdias. 13 de maio uma mentira cívica. Discurso proferido pelo Senador Abdias Nascimento por ocasião dos 110 anos da Abolição no Senado Federal. Brasília, 1998. Disponível em https://www.geledes.org.br/abdias-nascimento-13-de-maio-uma-mentira-civica-2/. Acesso em 27 out. 2020.

NUNES, Mônica; WANDERER, Fernanda. Escola e relações étnico-raciais: uma análise sobre enunciações de alunos. Perspectiva, Florianópolis, v. 37, n. 1, p. 275-295, jan./mar. 2019.

OLIVEIRA, Paula Cristina Silva de; SILVA, Andressa Carvalho da. Ressignificação da identidade negra em uma escola no Distrito de Sopa, Diamantina - MG. Olb@res, São Paulo, v. 3, n. 1, p. 258279, 2015.

PEREIRA, Arliene Stéphanie Menezes; GOMES, Daniel Pinto; CARMO, Klertianny Teixeira do; SILVA, Eduardo Vinicius Mota E. Aplicação das leis 10.639/03 e 11.645/08 nas aulas de educação física: diagnóstico da rede municipal de Fortaleza/CE. Revista Brasileira de Ciências do Esporte, Brasília, n. 6, p. 1-7. 2018.

PEREIRA, Rinaldo Pevidor. O jogo africano mancala e o ensino de matemática em face da Lei 10.639/03. 2011. 156f. Dissertação (Mestrado em Educação) - Universidade Federal do Ceará, Faculdade de Educação, Programa de Pós-graduação em Educação Brasileira, Fortaleza - CE, 2011.

PERON, Mauro Luiz. Técnicas de Vídeo. In: VENTURI, Luís Antônio Bittar (org.) Geografia: práticas de campo, laboratório e sala de aula. São Paulo: Sarandi, 2011. p. 435-446.

RODRIGUES, Ruth Meyre Mota. Educação das relações étnico-raciais e gestão educacional. In: XV Simpósio Brasileiro e II Simpósio Ibero Americano de Politica e Administração da Educação: construção histórica, debates contemporâneos e novas perspectivas. ANPAE, São Paulo - SP, 2011. Disponível 
http://www.anpae.org.br/simposio2011/cdrom2011/PDFs/trabalhosCompletos/comunicacoes Relatos/0480.pdf. Acesso em 5 maio 2019.

RODRIGUES, Leandra Aparecida Mendes dos Santos. Documentos oficiais e legislações educacionais no combate às desigualdades raciais: estudo com base na PNAD. Reveduc, 2020.

SANTANA, Janaína de Jesus Lopes; OLIVEIRA, Matheus Alencar Fernandes; MACHADO e SILVA, Regina Coeli. O estudo daqui é o medo de lá: implementação da lei 10.639/03 nos livros didáticos. Educação e (Trans)formação, v. 3, n. 1, p. 97-112, 2018.

SANTOS, Sales Augusto dos. A Lei n. 10.639/03 como fruto da luta anti-racista do Movimento Negro. In: Educação anti-racista: caminhos abertos pela Lei Federal n. 10.639/03 / Secretaria de Educação Continuada, Alfabetização e Diversidade. Brasília: Ministério da Educação, Secretaria de Educação Continuada, Alfabetização e Diversidade, 2005.

SILVA, Rafael Celestino da; FERREIRA, Márcia de Assunção. Construindo o roteiro de entrevista na pesquisa In: Representações sociais: como, por que, para que. Esc Anna Nery, v. 16, n. 3, p. 607611, jul.-set., 2012. Disponível em https://www.scielo.br/j/ean/a/wMctqmZpKpYNdy8nZpTxJkp/?lang=pt. Acesso em 24 out. 2021.

SOUZA, Florentina da Silva; PEREIRA, Leticia Maria da Souza. Implementação da Lei 10.639/2003: mapeando embates e percalços. Educar em Revista, Curitiba, n. 47, p. 51-65, jan./mar. 2013.

SOUZA, Maicelma Maia; CRUSOÉ, Nilma Margarida de Castro; MOREIRA, Nubia Regina. Limitações da formação docente evidenciadas na prática pedagógica: trato com o tema das Relações Étnico-Raciais. Práxis Educacional. Vitória da Conquista v. 12, n. 21 p. 339-363 jan./abr. 2016.

SULEIMAN, Bianca Barbosa. Psicologia e Ensino das Relações Étnico-Raciais: uma experiência na formação de professores. Psicol. Esc. Educ., Campinas, v. 18, n. 2, p. 369-372, ago. 2014.

TUAN, Yi-Fu. Topofilia: um estudo da percepção, atitudes e valores do meio ambiente. Trad. Lívia de Oliveira. Londrina: Eduel, 2012.

\section{Informações das autoras}

Leandra Aparecida Mendes dos Santos Rodrigues

Secretaria da Educação do Estado de Goiás

E-mail: leandra.aparecida@hotmail.com

ORCID: https://orcid.org/0000-0003-0723-3520

Link Lattes: $\underline{\text { http://lattes.cnpq.br/1151524637468229 }}$

Mayara Lustosa de Oliveira Barbosa

Instituto Federal de Brasília

E-mail: mayara.barbosa@ifb.edu.br

ORCID: https://orcid.org/0000-0003-3356-0998

Link Lattes: http://lattes.cnpq.br/5021830666471504 